\title{
Analysis of Factors for Implementing TPM: A Study in Welded Tube Manufacturers
}

\author{
Rodolfo Alves de Oliveira, Jorge Muniz Jr., and Fernando A.S. Marins \\ Universidade Estadual Paulista (UNESP), Guaratingueta, Brazil \\ \{jorgemuniz, fmarins\} @feg.unesp.br
}

\begin{abstract}
This study aims to identify and assess critical factors influencing on the implementation of continuous improvement projects, specifically the TPM. This research is a quali-quanti study and collects data with managers who lead TPM implementation in the shop floor. In this perspective, the present work can contribute to production managers with an assessment of the critical factors that will assist in decision-making processes for implementing improvement projects and troubleshooting methods, more specifically based on the TPM and Autonomous Maintenance.
\end{abstract}

Keywords: Total Productive Maintenance. Critical factors. Continuous improvement projects. Welded tube industries.

\section{Introduction}

Companies seek solutions to increase their profitability through eliminating losses, reducing time spent in models and tools exchange, setting standards of speed to productive machines and improving the final quality of products $[3,4]$. With a view of improving operational performance, continuous improvement programs have been run with control and production management tools.

It is discussed the influence of contextual factors as size, age of the plant, and the influence of the workmen union of the sector in successful TPM's implementation, and other good production practices [6,7].

This study aims to identify and assess critical factors influencing on the implementation of continuous improvement projects, specifically the TPM. This research is a quali-quanti study and collects data with managers who lead TPM implementation in the shop floor.

Autonomous maintenance aims to increase operational uptime of equipment through training and involvement of operational staff, but this goal can be hindered if there is an inadequate implementation of the program, blurring in planning, coupled with a lack of top management support and commitment of the staff.

Searching for better results, for the solution of recurring problems and due to fierce competition, the industrial sector has been striving to carry out improvement projects, targeting gains through the implementation of appropriate tools, among which the TPM stands out, but it is necessary to monitor, track and identify the critical success factors involving the entire staff.

B. Grabot et al. (Eds.): APMS 2014, Part I, IFIP AICT 438, pp. 523-530, 2014.

(C) IFIP International Federation for Information Processing 2014 
In this perspective, the present work can contribute to production managers with an assessment of the critical factors that will assist in decision-making processes for implementing improvement projects and troubleshooting methods, more specifically based on the TPM and Autonomous Maintenance.

The present work is structured into sections. Section 2 presents a theoretical exploratory review that discusses continuous improvement, TPM and Critical Success Factors. In Section 3, it is presented the used research method. Section 4 discusses the case study on the metallurgical industry and the Critical Success Factor for the improvement project are consolidated. Section 5 presents the final considerations, followed by references.

\section{Theoretical Basis}

Critical factors for a successful implementation of TPM are need for training, allocation of necessary resources, definition of workload and an autonomous working group focused on the TPM [4]. It was registered gains of $83 \%$ increase in productivity, and a reduction in the rate of 517 machine stops for 89 times [4].

The literature analysed indicates a methodology that uses computational resources through a system developed to compare the losses of different machines and equipment by the OEE and identify the hidden times that saddled the process [5]. There are applications of Single Minute exchange of dies (SMED) methodology added to Method Time Measurements (MTM) to preserve the best arrangement through standardization to be incorporated by the TPM [3].

It is also explores the use of the SMED and its relevance in studying tools exchange, particularly the reduced-time ones [2]. The present study did not use the SMED, but notes the importance of attention in quick exchanges. Next, it is going to be demonstrated significant gains revaluating and redefining operation routines, but the author goes further and emphasizes that it must be applied during the development and design of equipment. Table 1 presents the definitions for the Critical Success Factors adopted in this paper.

Table 1. Definition of the Identified Critical Success Factors

\begin{tabular}{|c|c|}
\hline Critical Success Factor $(\mathrm{CF}$ & Description \\
\hline $\begin{array}{l}\text { 1. Top Management } \\
\text { Commitment }\end{array}$ & $\begin{array}{l}\text { Full support by Top managers of the company in following, participating } \\
\text { and monitoring actions for the result. }\end{array}$ \\
\hline 2. Project Financing & $\begin{array}{l}\text { Financial contribution that must be measured and invested in the program } \\
\text { for fulfilling all steps necessary to achieve the expected results [4]. }\end{array}$ \\
\hline $\begin{array}{l}\text { 3. Responsibilities Defini- } \\
\text { tion }\end{array}$ & $\begin{array}{l}\text { Definition of the ones who are directly responsible for the project, with } \\
\text { autonomy and authority to assign responsibilities to the staff }[4],[6] \text {. }\end{array}$ \\
\hline $\begin{array}{l}\text { 4. Adopted Methodology } \\
\text { and Scope }\end{array}$ & $\begin{array}{l}\text { Tools and methods defined for the project implementation, the way in which } \\
\text { it was sectioned a more comprehensive program in relation to the initially } \\
\text { defined scope [4]. }\end{array}$ \\
\hline 5. Steps Planning & $\begin{array}{l}\text { Fulfillment of the previously established steps, respecting necessary time } \\
\text { and sequence for the project success [4]. }\end{array}$ \\
\hline
\end{tabular}


Table 1. (continued)

\section{Leadership}

7. Training

8. Supporting areas

9. Management Dedication

10. Workload

11. Goals and Indicators

12. Staff Motivation

13. Staff Commitment
The needed profile of the Leader for conducting teamwork, with influence and motivation to seek results, assumptions which are fundamental for the project success.

Personnel training, knowledge dissemination, and information level equalization among all those involved [2,3,4].

Support and assistance that should be given by the support areas that are not directly involved in the project.

Attention that must be devoted by a part of the Managers in the actions defined by the group that are not associated to routine activities, giving them due importance and providing necessary resources [4].

Definition of the activities and an association of routine with the dedication needed by the whole staff in relation to the project [3].

Definition of indicators that are aligned and have an interaction with business objectives. Bold targets, but compatible with projects underway $[2,3,4,5]$.

Recognition of the achieved work and applicability of developed projects in order to contribute to the growth of the company and generate gains for the staff [4].

Commitment of each staff member with a continuous improvement [6].

\section{Research Method}

This study was developed in two metallurgical industries of São Paulo, the most industrialized State in Brazil, which are manufacturers of carbon steel products for the industrial, oil and gas sectors for the national and international markets (Table 2).

Table 2. Companies Description

\begin{tabular}{ccc}
\hline & Company 1 (E1) & Company 2 (E2) \\
\hline Employees & 350 & 450 \\
Annual Turnover & $\mathrm{R} \$ 60$ and 110 million / year & $\mathrm{R} \$ 40$ and 90 million / year \\
Productivity & 110 thousand ton / year & 70 thousand ton / year \\
Time in operation & Over 50 years & Over 50 years \\
\hline
\end{tabular}

The sectors defined for carrying out these projects were conformation and welding, involving a group of professionals of different levels and areas of expertise.

The open questionnaire was comprised of questions as follows. It sent by email to 5 leaders who held leadership positions in the company's structure.

a) In your opinion, what does it take for an implementation project of Autonomous Maintenance to succeed? Why?

b) Given the assessment made on question (a), answer: what was missing and/or undermined the implementation of Autonomous Maintenance and TPM in the unit? Why? 
c) What do you expect from the TPM implementation in the unit? Which results? Why?

The respondents are Project Leaders of implementation. They are professionals with technical training dedicated to shop floor management, all with years of experience in the metallurgical industry. Open interview responses were obtained with professionals in the following profiles: 4 Improvement project Leaders in company 1 (E1) and 1 improvement project leader in company 2 (E2). The open interview was analyzed according to the method of Content Analysis defined [1].

A closed questionnaire was elaborated in order to obtain the opinion of each of the respondents on the order of importance of each of the 13 Critical Success Factors obtained in the open interview.

Respondents were asked to indicate the most important factor with the number 1 , and so on until the number 13, the least important, in the column called "Rating" on the Survey Form of the Critical Success Factors. The closed questionnaire was conducted with 12 leaders with $83 \%$ return of responses.

Both companies launched their programs with embryonic projects. As mid-size companies, they invested in continuous and manufacturing processes improvement within possible. The need to establish a position on the market and modernize the plant significantly reduced investment aid in modern management tools that require more extensive programs. However, the quest for better results has led these companies to adopt some programs of continuous improvement in a fragmentary form. In this study, it was adopted the Autonomous Maintenance that represents only one of the pillars of the TPM.

Data management and ordering Critical Success Factors aims to highlight those that were considered of utmost importance. Table 3 presents the weightiness assigned to each of the 13 factors.

Table 3. Importance Indication and assigned weight for indication

\begin{tabular}{ccccccc}
\hline $\begin{array}{c}\text { Importance } \\
\text { Indication }\end{array}$ & 1 & 2 & 3 & 4 & 5 & 6 to 13 \\
\hline $\begin{array}{c}\text { Assigned } \\
\text { Weight }\end{array}$ & 100 & 75 & 50 & 25 & 10 & 1 \\
\hline
\end{tabular}

\section{Results Analysis}

Detailed data on respondents and companies can be found in the Appendix. According to Leaders of company E1, the CSF1 (Top Management Commitment) was appointed as being the most important factor, which was also appointed by Leaders of company E2. Another coincidence was the CSF11 (Indicators and Targets) were ranked as the fourth most important factor in both companies. However, other rated factors follow their own characteristics. CSF9 (Management Dedication) appears in second, CSF5 (Steps Planning) in third, and CSF3 (Definition of Responsibilities) was ranked as the fifth most important factor. 
It is noted that the most important critical factors presented by Leaders of company E1 demonstrate its structural and sizing needs, i.e. it is not clear what resources are available and the adopted standardization through measurements and targets for achieving project success, pointing also to financial aid, staff motivation and leadership profile, basic factors that must be previously defined.

The result of the assessments made by Leaders of company E2 show needs for planning, organization and defining responsibilities for the project to succeed.

By comparing the results of assessments carried out by Leaders of companies E1 and E2, it is possible to observe that company E1 lacks basic structural definitions, while leaders of company E2 direct their actions towards activities organization and project participant assignments.

Note that in a joint evaluation of the results obtained between E1 and E2 companies, as shown in Figure 8, the ratings of Critical Success Factors changes again. Figure 1 presents the ratings of factors with a joint assessment. Top Management Commitment (CSF 1) is indicated as the most important factor to both companies. Some results of the TPM implementation were identified along the survey, as Table 4. In these projects, even though it has been an attempt of partial implementation and despite the flaws in program structure, it was found that the analyzed companies had significant gains.

The reduction in time of tool exchange generated gains of $\mathrm{R} \$ 42,835.06 /$ year to company E1 and $\mathrm{R} \$ 10,162.60 /$ year to company E2. The improvement work in productivity involved other actions focused on machines performance that go beyond the work conducted on non-detailed Machines Stops. However, reducing time span and considering the productivity achieved after the improvements indicated a potential annual savings of $\mathrm{R} \$ 723,644.23$ to company $\mathrm{E} 1$ and $\mathrm{R} \$ 333,959.81$ to company $\mathrm{E} 2$.

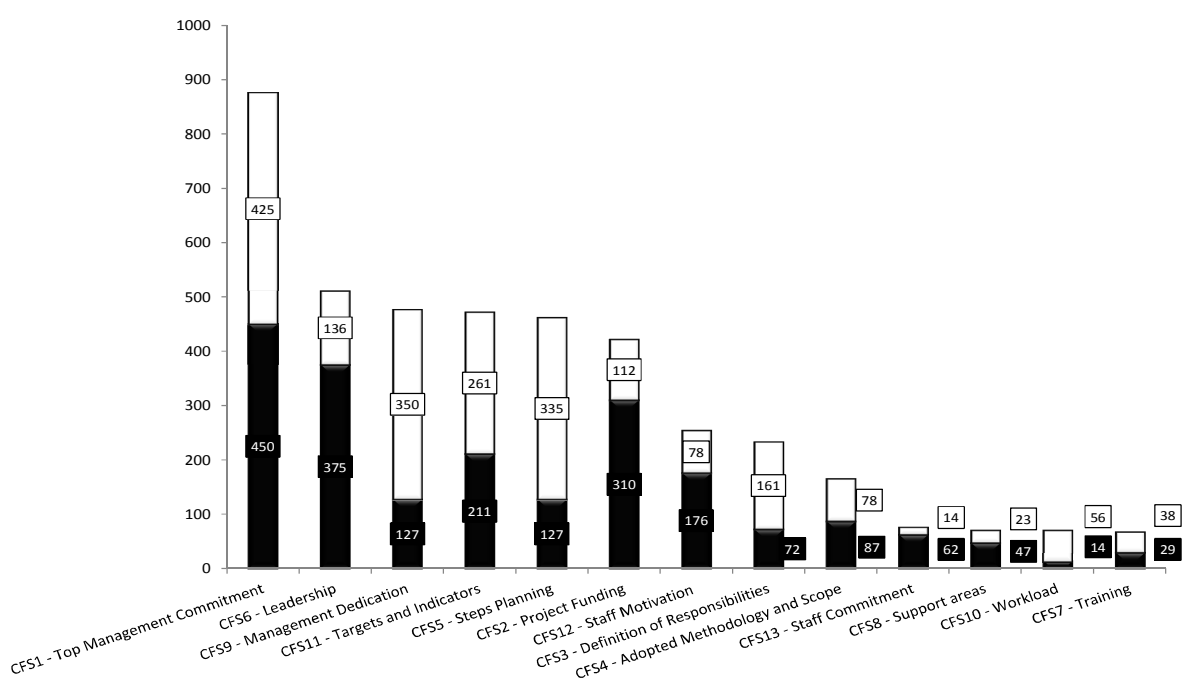

Fig. 1. Assessment of Critical Factors 
Table 4. Gains (2007-2009)

\begin{tabular}{ccccc}
\hline Item & Before & After & Gain & Company \\
\hline & 43,08 & 28,54 & $33,75 \%$ & E1 \\
Tool Exchange [h/month] & 12,68 & 10,52 & $17,03 \%$ & E2 \\
& 1,47 & 0,51 & $65,31 \%$ & E1 \\
Machine Stops "minor events" [h/shift] & 2,51 & 1,27 & $49,49 \%$ & E2 \\
Production Availability [h/ shift] & 7,53 & 8,49 & $12,75 \%$ & E1 \\
& 6,49 & 7,73 & $19,09 \%$ & E2 \\
\hline
\end{tabular}

\section{Conclusion}

This study aimed to identify the determining factors for the success of implementing the TPM from managers' perspective. Top Management Commitment, Leadership, Management Dedication, Indicators and Targets, and Steps Planning were identified and assessed.

Furthermore, this study is also proposed to present positive results, but warns that savings could have been greater if the program had been restructured, even if abiding by a prior decision to be implemented just under the pillar of Autonomous Maintenance, being reoriented by factors herein indicated, though.

There is coherence among the results and the literature by presenting similar factors. This indicates that the factors analyzed are similar independent the sector researched.

This paper presented coherence between the analyzed companies in relation to the Critical Success Factor of greatest importance, both pointing to the lack of commitment by Top Management as being determinant for success.

It is noteworthy that positive and proven results that are routinely divulged in several specialized communication media induce companies' managers to adopt, even without preparation or pre-planned improvement programs, however, often by ignorance and/or being poorly advised, a partial implementation of a complete and extensive program as the TPM, as it was highlighted in this work into which two companies had adopted only the Autonomous Maintenance which is just one of the TPM pillars, without following the steps and adequately predicting necessary investments.

There are no impediments to adopting partial programs, regardless of the reasons for the decision, even if it were a strategic definition, steps must assessed and sized. It is crucial to define and present clear objectives in order not to generate expectations on the team, and avoid losses and disrepute if the program is extended or resumed in the future.

This work showed that the competitive differential between capital goods companies that act with commodities, which are goods with prices (pre)defined by the market, lies in continuous improvement, and that programs which are properly 
implemented with support from Top management could mean the survival of the business.

Staff participation and contact with the culture of continuous improvement, necessary to introduce the concepts of Autonomous Maintenance, brought changes in behaviour for all those involved in both companies, in the form of seeing and participating in results in a more active way, in the perception that it actually adds value to product, and even in their attitude towards safety.

As proposal for further work, it is suggested the use of decision making methods with multiple criteria, such as the Analytic Hierarchy Process (AHP) for assigning weights that were arbitrarily set, aiming to highlight the 5 most important critical factors, as shown in item Section 3 (Table 3). It is also recommended the use of statistical methods and software for evaluating results. The AHP can give more accuracy in the weights set for each factor.

It would be interesting to deepen in performance results, extending to sales lead and measuring profit, not only comprising savings that reflect in production costs, as presented in this study, but going beyond the definition of the Critical Factors and introducing boundary conditions and delimitations in order to effectively restructure the adopted program, and make a comparison between a complete program and a partially implemented one.

\section{References}

1. Bardin, L.: Content Analysis (Análise de Conteúdo), 5th ed., Edições 70, Lisboa, Portugal (2008) (Portuguese)

2. Cakmakci, M.: Process improvement: performance analysis of the setup time reductionSMED in the automobile industry (2008)

3. Cakmakci, M., Karasu, M.K.: Set-up time reduction process and integrated predetermined time system MTM-UAS: A study of application in a large size company of automobile industry (2006)

4. Chan, F.T.S., Lau, H.C.W., Ip, R.W.L., Chan, H.K., Kong, S.: Implementation of total productive maintenance: A case study. Hong Kong: Int. J. Production Economics (2003)

5. Joeng, K.-Y., Phillips, D.T.: Operational efficiency and effectiveness measurement, USA (2001)

6. Shah, R., Ward, P.T.: Lean manufacturing: context, practice bundles, and performance. Journal of Operations Management 21, 129-149 (2003)

7. Muniz Jr., J., Batista, J.B., Batista Jr., E.D., Loureiro, G.: Lean Management Practice: Toyota Brazilian Plants Case. In: POMS - Production and Operations Management Society, Denver (2013) 


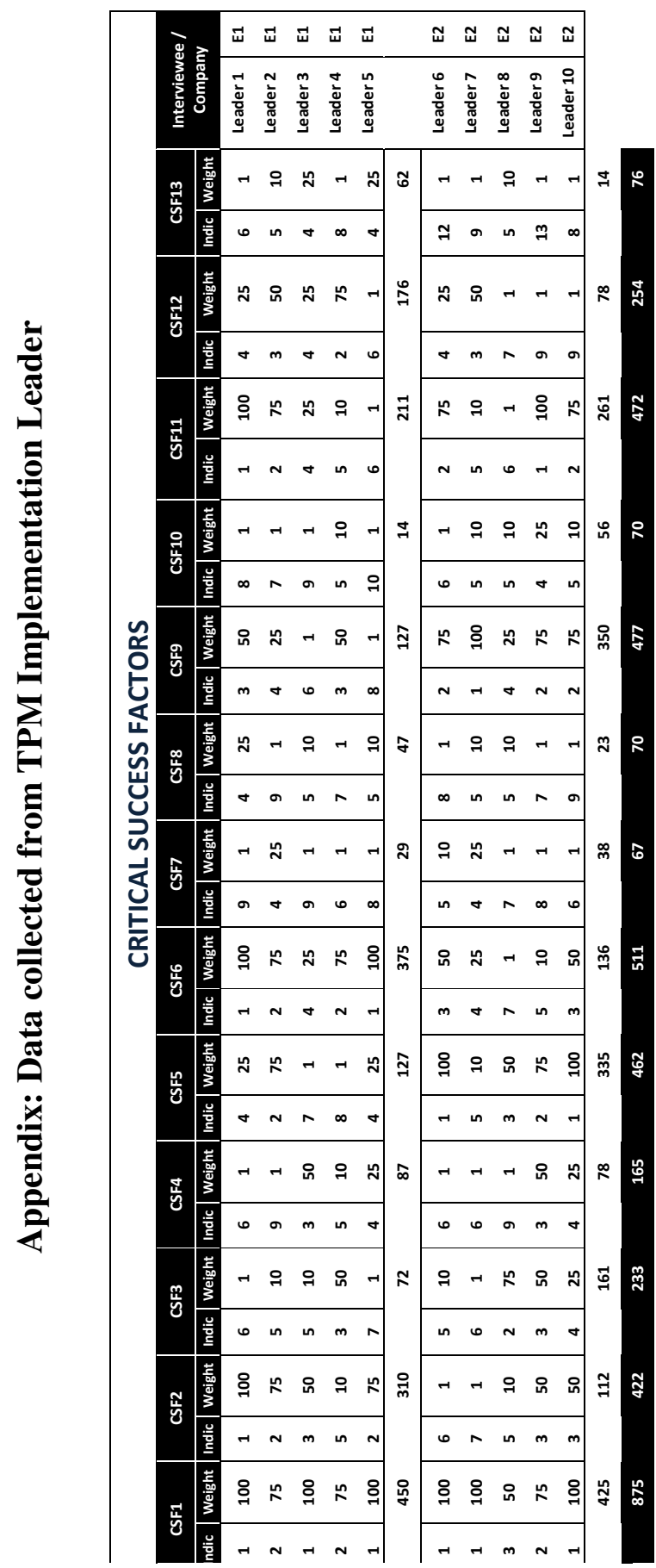

